\title{
Laboratory Investigation on the Interface Bonding between Portland Cement Concrete Pavement and Asphalt Overlay
}

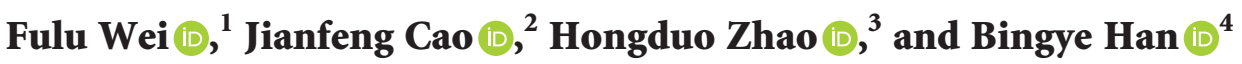 \\ ${ }^{1}$ China Construction Eighth Engineering Division Co., Ltd., Shanghai 200122, China \\ ${ }^{2}$ China Harbour Engineering Co. Ltd., Beijing, China \\ ${ }^{3}$ The Key Laboratory of Road and Traffic Engineering, Ministry of Education, Tongji University, Shanghai 201804, China \\ ${ }^{4}$ School of Civil and Transportation Engineering, Beijing University of Civil Engineering and Architecture, \\ No. 1 Zhanlanguan Road, Xicheng District, Beijing 100044, China
}

Correspondence should be addressed to Bingye Han; hanbingye@bucea.edu.cn

Received 15 September 2020; Revised 25 November 2020; Accepted 10 March 2021; Published 22 March 2021

Academic Editor: Sébastien Poncet

Copyright (c) 2021 Fulu Wei et al. This is an open access article distributed under the Creative Commons Attribution License, which permits unrestricted use, distribution, and reproduction in any medium, provided the original work is properly cited.

\begin{abstract}
The interface bonding between Portland cement concrete (PCC) pavement and hot-mix asphalt (HMA) overlay plays an important role in the performance of the composite pavement. This research conducted a series of comprehensive laboratory studies to investigate the influence factors of the interface bonding strength using a self-designed direct shear test apparatus that can simultaneously apply normal stress and shear stress on a specimen. Four kinds of commonly used tack coat materials were systematically tested and compared under various combinations of normal stress and temperature. Then, coupling effects of the normal stress and temperature on the interface bonding between PCC and HMA were analyzed. The test results show that temperature has a significant impact on the adhesion of the tack coat. Emulsified asphalt was considered the optimal tack coat material because of its simple construction method. In addition, it was found that a damaged interface could still provide considerable bonding strength. Normal stress generated by traffic loads was beneficial to the interface bonding strength, especially at lower temperatures. The temperature had a significant effect on interface bonding and played a leading role in the failure mode of interface bonding.
\end{abstract}

\section{Introduction}

The interface bonding between Portland cement concrete (PCC) pavement and hot-mix asphalt (HMA) overlay is widely recognized as one of the most critical influence factors on mechanical responses of composite pavement as well as its long-term performance [1-3]. Several studies have revealed that a weak interface bonding strength will undoubtedly cause higher bending stress, shear stress, and deflection in the composite pavement, resulting in some unexpected pavement distresses $[3,4]$. In the worst case, the HMA overlay might encounter problems such as slippage cracking, delamination, or severe rutting [5-10]. These facts highlight the important role of interface bonding in composite pavement. So far, most studies have focused on the influence factors of interface bonding and experimental test methods or equipment. Nevertheless, these studies have not been widely accepted by researchers and engineers due to lack of sufficient supporting data [11-14].

In the past few decades, many equipment and methods have been developed for studying the interface boding, including direct shear test, pull-off test, and torsional shear test $[15,16]$. The direct shear test is one of the most used methods to investigate the interfacial adhesive properties of multilayer materials or structures. Generally, in terms of the stress field applied during the test, the direct shear test includes pure direct shear test and direct shear test with normal stress. The pure direct shear test only applies shear force to the interface of specimen without normal stress, such as Superpave shear tester [17], Leutner shear test [14], Laboratory Bond Interface Strength device [18], and Florida Department of Transportation shear tester [19]. However, 
there is almost no pure shear stress state in the interface of composite pavement. Considering the influence of normal stress, it is more in line with the actual situation. Uzan et al. [11] designed a direct shear box that can apply both normal and shear loads on the interface of the double-layered prismatic specimen to measure the stiffness $\mathrm{K}$ under different test conditions. Donovan et al. [20] developed a device to determine the optimum dosage of tack coat for a PCC bridge deck overlaid with geomembrane and HMA layer. AlQadi et al. [15] modified a direct shear tester that can apply normal load in the horizontal direction and shear load in the vertical direction. Arulrajah et al. [21] evaluated the interface shear strength through a large-scaled direct shear apparatus. The American Association of State Highway and Transportation Officials (AASHTO) standard also recommended a method using Louisiana Interlayer Shear Strength Tester to test the interlayer shear strength between asphalt pavement layers [22]. In the above equipment, it is recommended to use a device that can apply both normal load and direct shearing force since it can obtain the interface bonding strength of the specimen under a more realistic stress state.

It has been widely accepted that the mixture type, PCC surface texture, tack coat material, application rate of tack coat, normal stress on the interface, and temperature are the main influence factors affecting the interface bonding strength between HMA overlay and PCC layer [23-25]. For instance, a study pointed out that the interfacial shear strength at $25^{\circ} \mathrm{C}$ is about five times that of high temperature at $55^{\circ} \mathrm{C}$. Ge et al. [26] conducted a series of orthogonal experiments using the shear test method to evaluate the impact of temperature, bonding material, and confining pressure, but the study mainly investigated the benefits of glass fiber reinforced asphalt membrane. Leng et al. [23] used a direct shear tester to study several influence factors, including HMA type, tack coat type, tack coat application rate, PCC surface texture, and temperature. The investigation concluded that SS-1hP asphalt emulsion shows a better performance than RC-70 cutback asphalt, and the optimum application rate of tack coat is $0.27 \mathrm{~L} / \mathrm{m}^{2}$. Moreover, compared with high temperature, the lower temperature is beneficial to interface bonding strength. Later, an accelerated pavement testing (APT) was conducted in 2008 to verify some of these findings [24]. However, these two investigations have some limitations. Firstly, only two kinds of HMA mixtures and tack coat materials were included in the test, which limited the distribution of these findings. Secondly, the studies ignored the effects of normal stress on interface bonding, but the normal stress was so important that it could not be ignored, which made the conclusions unconvincing. Finally, the coupling effect of normal stress and temperature were also not considered. The authors believe that more efforts are needed to focus on more influence factors affecting interface bonding. It is also of great significance to investigate the interfacial bonding strength between HMA overlay and PCC pavement.

The objective of this study is to investigate the influence factors that affect interface bonding strength between HMA overlay and PCC layer through a series of laboratory tests. To fulfill this purpose, a self-designed direct shear tester was developed, and both normal load and shear force could be applied to the specimen at the same time. Four types of tack coat materials, five different test temperatures, and four different normal stresses were considered, and the coupling effect of temperature and normal stress was further analyzed.

\section{Methodology}

2.1. Test Apparatus. Considering the effects of normal stress on interface bonding between HMA overlay and PCC layer, an upgraded direct shear test apparatus was developed, and more details about the device can be found in the previous research [25]. The equipment is able to apply normal stress in a horizontal direction through a hydraulic actuator, and the magnitude of normal stress can be obtained by a built-in stress sensor, as shown in Figure 1(a). However, the direct shear tester itself cannot apply the shear force to the specimen. Therefore, a material testing system (MTS) is employed to apply the shear force on the loading plate under a displacement control mode with a constant shearing rate of $2.5 \mathrm{~mm} / \mathrm{min}$ in accordance with the AASHTO standard [22]. Specimen slot is designed for a double-layer specimen whose size is $150 \mathrm{~mm}$ in diameter and $100 \mathrm{~mm}$ in height. The MTS's environment cabinet was used to control test temperature.

2.2. Material and Specimen Preparation. In this study, four types of tack coat were investigated, including cutback asphalt, anionic emulsified asphalt, rubber asphalt, and virgin asphalt. Table 1 lists the properties of the four tack coats. This study adopted the manufacturer-recommended optimal application rate of tack coat (i.e., $0.33 \mathrm{~L} / \mathrm{m}^{2}$ for cutback asphalt, $0.31 \mathrm{~L} / \mathrm{m}^{2}$ for emulsified asphalt, and $0.27 \mathrm{~L} / \mathrm{m}^{2}$ for the rests). Commonly, the curing time of cutback asphalt and emulsified asphalt was two hours and half an hour, respectively.

As mentioned above, the specimen used for the direct shear test is composed of two layers of materials, PCC and HMA, as shown in Figure 1(b). Firstly, a concrete core sample was drilled from a $50 \mathrm{~mm}$ thick PCC slab with a smooth surface. Then, the hot-mix asphalt mixture was compacted on the surface of the concrete core sample using a Superpave Gyratory Compactor (SGC). Figure 2 shows the aggregate gradation of the HMA mixture. According to the Marshall design method, the optimum binder content was $4.5 \%$ when using the virgin asphalt.

2.3. Data and Parameters. The pretest result shows that there were two typical shear stress-displacement curves for the direct shear test, which represented brittle failure and plastic failure, respectively. As shown in Figure 3, the shear stress reduced dramatically after reaching its peak value for the brittle-failure curve. In contrast, the shear stress of plastic failure did not show a clear decrease trend during the whole test. To describe the characteristics of interface bonding thoroughly, this study used four parameters, including shear strength, interface bonding coefficient (IBC), residual strength, and residual ratio. 


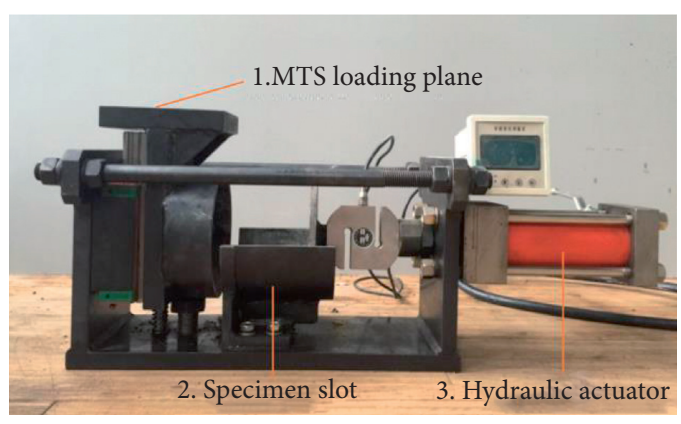

(a)

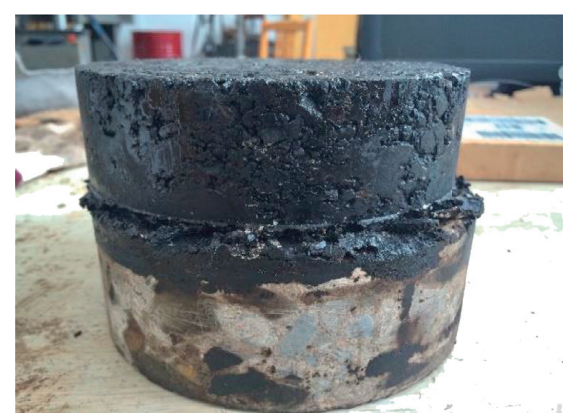

(b)

Figure 1: The test setup. (a) The shear test apparatus. (b) Specimen.

TABLE 1: Properties of tack coats.

\begin{tabular}{lcccc}
\hline Tack coat type & Penetration at $25^{\circ} \mathrm{C}(0.1 \mathrm{~mm})$ & Ductility $(\mathrm{cm})$ & Viscosity at $135^{\circ} \mathrm{C}(\mathrm{Pa} \cdot \mathrm{s})$ & Softening point $\left({ }^{\circ} \mathrm{C}\right)$ \\
\hline Rubber asphalt & 53.2 & 35.5 & 2.23 & 72.6 \\
Virgin asphalt & 62.4 & 123 & 0.56 & 48.3 \\
Emulsified asphalt & 67.8 & 57.7 & 0.7 & - \\
Cutback asphalt & 65.1 & 129 & 0.6 & - \\
\hline
\end{tabular}

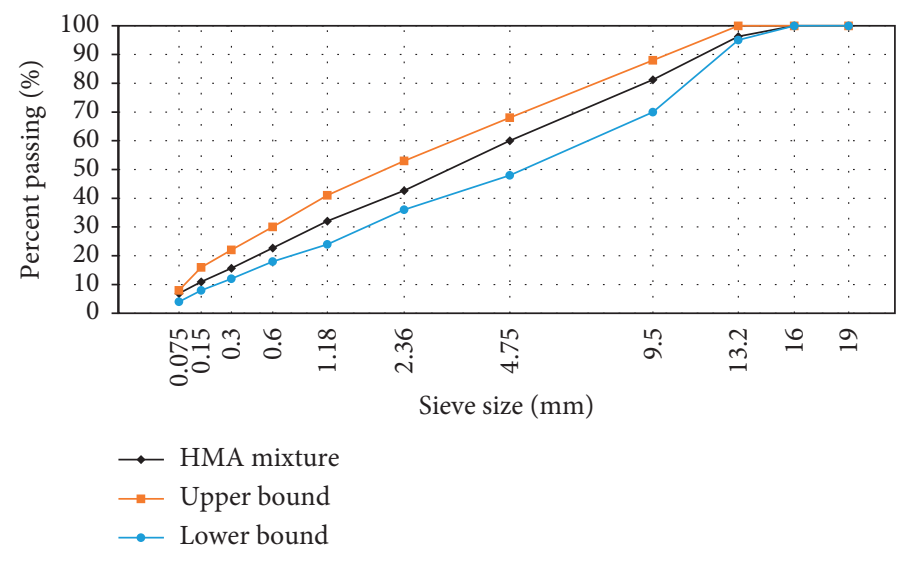

FIgURE 2: Aggregate gradation of HMA mixture.

2.3.1. Shear Strength. Shear strength is the peak shear stress in the direct shear test, which can be determined from equations (1) and (2). For the brittle-failure curve, it is easy to obtain the peak shear stress. However, it is complex to get the peak value in the plastic failure curve due to a lack of evident peak value. After in-depth inspection and analysis of most plastic failure curves, the authors found that it is reasonable to use the shear stress at the shear displacement of $5 \mathrm{~mm}$ as its shear strength. Therefore, the shear strength for the plastic failure curve is determined according to equation (2):

$$
\begin{aligned}
\tau & =\frac{F}{A}, \\
\tau_{\max } & = \begin{cases}\max (\tau), & \text { Brittle failure, } \\
\tau(\text { displacement }=5 \mathrm{~mm}), & \text { Plastic failure, }\end{cases}
\end{aligned}
$$

where $\tau$ is shear stress, $\mathrm{MPa}$; $\tau_{\max }$ is shear strength, $\mathrm{MPa} F$ is shear force applied by MTS, N; and $A$ is the cross section area of the specimen, $\mathrm{mm}^{2}$.

2.3.2. Interface Bonding Coefficient. Interface bonding coefficient (IBC) is a parameter introduced in the Goodman contact model [27], as defined in equation (3). In 1978, Uzan et al. [11] firstly adopted IBC to evaluate the interface contact issue. IBC is the shear stiffness of interface bonding. A higher IBC value indicates that the interface bonding tends to brittle failure, while a lower IBC implies that the interface bonding is prone to plastic failure:

$$
K=1000 \times \frac{\tau_{\max }}{\Delta \mu},
$$




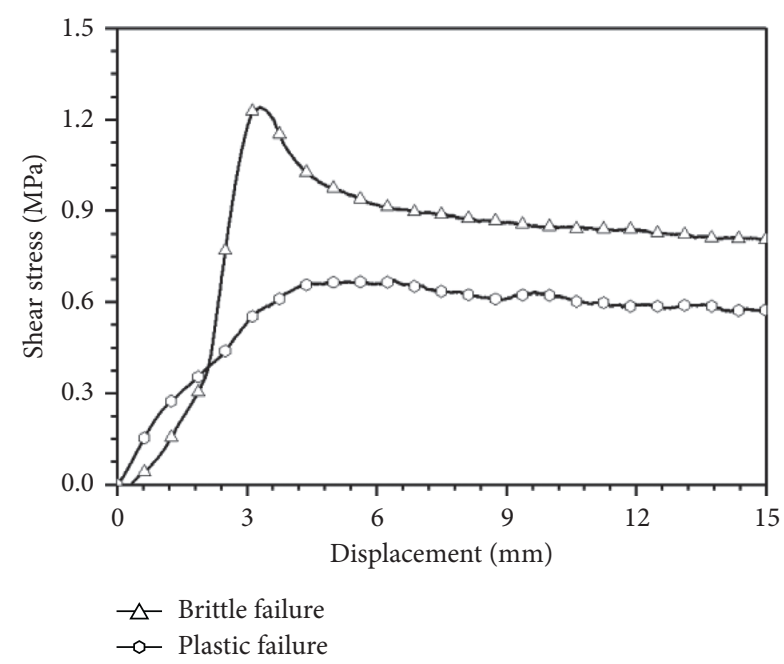

Figure 3: Two typical shear stress-displacement curves from the direct shear test.

where $K$ is interface bonding coefficient, $\mathrm{N} / \mathrm{cm}^{3} ; \tau_{\max }$ is shear strength, $\mathrm{MPa}$; and $\Delta \mu$ is the displacement corresponding with its shear strength, $\mathrm{mm}$.

2.3.3. Residual Strength and Residual Ratio. As shown in Figure 3, the interface bonding of the specimen does not completely lose its strength after reaching the peak shear stress. Actually, the residual strength of the interface bonding is still high, especially for plastic failure specimen, which suggests that the interface bonding strength between HMA overlay and PCC layer might be still good enough, even if suffering damage. Therefore, it is meaningful to study the residual strength's properties. In this investigation, the residual strength is empirically defined as the shear stress at a displacement of $10 \mathrm{~mm}$. Consequently, the residual ratio can be calculated by equation (4). In most cases, $R$ is less than 1 , but $R$ can also be greater than 1 in terms of its definition. It should be noted that the residual ratio of the brittle-failure curve is quite different from that of the plastic failure curve:

$$
R=\frac{\tau_{R}}{\tau_{\max }}
$$

where $R$ is residual ratio; $\tau_{R}$ is residual strength, MPa; and $\tau_{\max }$ is shear strength, MPa.

2.4. Test Plan. The laboratory investigation roughly includes two steps. The first step was aiming at further studying the influence of tack coat on interface bonding. Four types of tack coat materials, virgin asphalt, rubber asphalt, anionic emulsified asphalt, and cutback asphalt, were tested at $15^{\circ} \mathrm{C}$ and $45^{\circ} \mathrm{C}$ under $1.5 \mathrm{MPa}$ normal stress. Each test included three replicates. The second step was attempting to figure out the coupling effects of normal stress and temperature on the interface bonding by implementing a multifactorial experiment. Several different test temperatures between 0 and $60^{\circ} \mathrm{C}$, with an interval of $15^{\circ} \mathrm{C}$, were selected to represent actual high and low environmental temperatures in the East
China area. Test temperature included $0^{\circ} \mathrm{C}, 15^{\circ} \mathrm{C}, 30^{\circ} \mathrm{C}, 45^{\circ} \mathrm{C}$, and $60^{\circ} \mathrm{C}$, and the normal stresses contained $0 \mathrm{MPa}, 0.5 \mathrm{MPa}$, $1.0 \mathrm{MPa}$, and $1.5 \mathrm{MPa}$.

\section{Results and Discussion}

In this section, the shear strength, IBC, residual strength, and residual ratio were calculated based on laboratory test results. Both analysis of variance (ANOVA) and data analysis were employed to figure out the significant influence factors and internal mechanism of interface bonding between HMA overlay and PCC pavement.

\subsection{Determining the Optimal Tack Coat Material.} Figure 4 illustrates the typical shear stress-displacement curves for various tack coat materials at two different temperatures. All tests in this section were implemented under 1.5 MPa normal stress. It is obvious that the failure of interface bonding was tightly related to the test temperature. Low temperature was prone to lead to brittle failure and higher shear strength, while the high temperature was likely to cause plastic failure and lower shear strength. However, when cutback asphalt was used, no matter at $15^{\circ} \mathrm{C}$ or $45^{\circ} \mathrm{C}$, the interface bonding exhibited plastic failure. The possible reason was that the adhesion of cutback asphalt was weaker, and its plastic deformation was better. In this situation, the interface bonding was likely to form rolling friction.

It can be also found in Figure 4 that the test temperature had significant effects on the bonding performance of the tack coat. The adhesive ability ranking of tack coat based on the shear strength at $15^{\circ} \mathrm{C}$ was emulsified asphalt $>$ rubber asphalt $>$ virgin asphalt $>$ cutback asphalt. It should be noted that the shear strength of cutback asphalt was significantly lower than that of others. In contrast, the adhesive ability ranking at $45^{\circ} \mathrm{C}$ was virgin asphalt $>$ cutback asphalt $>$ rubber asphalt $>$ emulsified asphalt, which was quite different from the results at $15^{\circ} \mathrm{C}$.

Figure 5 illustrates the test results of various tack coat materials grouped by four interface bonding parameters. As shown in Figure 5(a), emulsified asphalt showed the highest shear strength at low temperature (i.e., $15^{\circ} \mathrm{C}$ ), following by rubber asphalt and then virgin asphalt. In contrast, the shear strength from cutback asphalt was significantly lower than others. However, the shear strength of emulsified asphalt and rubber asphalt became smaller at high temperature (i.e., $45^{\circ} \mathrm{C}$ ), while the virgin asphalt and cutback asphalt produced a higher shear strength. These facts indicated that temperature played an important role in the adhesive properties of tack coat, and the tack coat owning a high shear strength at low temperature might not provide similar bonding performance at high temperature. Therefore, considering the influence of temperature could be helpful to choose the proper tack coat material in engineering practice. In addition, the bonding properties of emulsified asphalt and rubber asphalt were more sensitive to temperature change.

Figure 5(b) shows the results of interface bonding coefficient (IBC) from different tack coat materials. Like the shear strength, emulsified asphalt, rubber asphalt, and virgin 


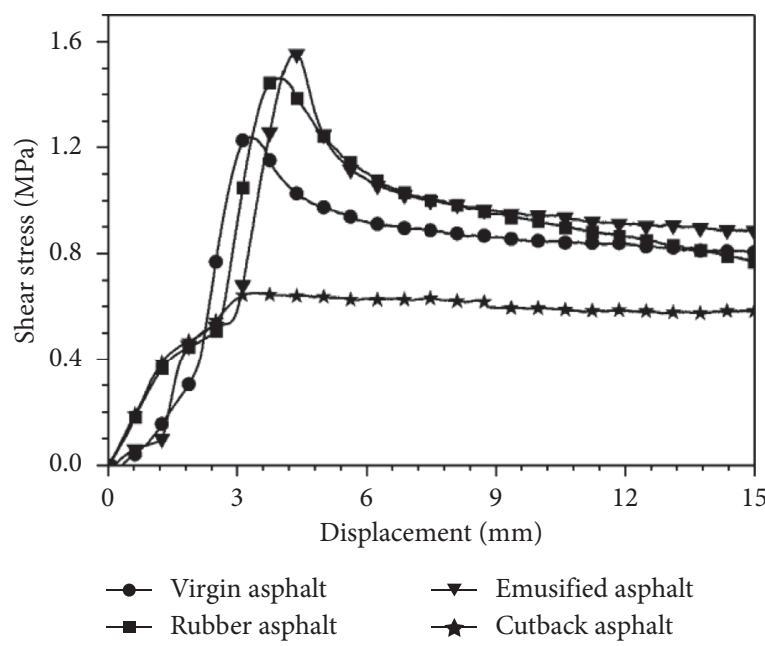

(a)

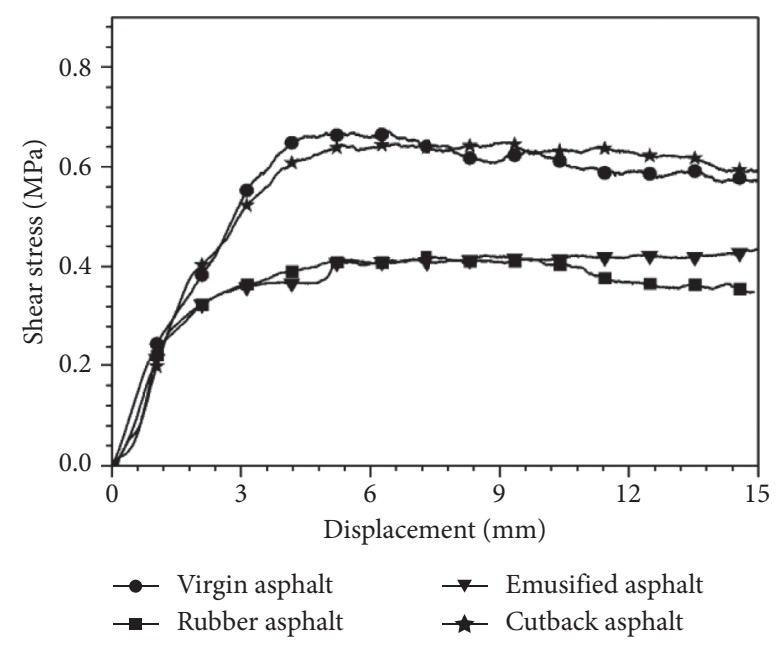

(b)

Figure 4: Shear stress-displacement curves at two different temperatures: (a) At $15^{\circ} \mathrm{C}$. (b) At $45^{\circ} \mathrm{C}$.

asphalt had higher IBC when the test temperature was at $15^{\circ} \mathrm{C}$. However, all IBC decreased significantly at $45^{\circ} \mathrm{C}$. Further study revealed that the brittle-failure specimens had higher IBC than plastic failure specimens. The IBC gap between brittle-failure specimens and plastic failure specimens suggested that the IBC of plastic failure might be less than a certain threshold value. Unfortunately, this study could not determine that value, and more tests were needed in the future.

The residual strength was used to characterize whether the interface bonding could still provide a certain strength after the interface bonding was damaged. Roughly, a specimen with higher shear strength was likely to have higher residual strength according to Figure 5(c), which meant that all residual ratios were at a high level. Residual ratios presented in Figure 5(d) were able to prove the above inference. The minimum residual ratio at $15^{\circ} \mathrm{C}$ and $45^{\circ} \mathrm{C}$ was $52.6 \%$ and $85 \%$, respectively. In other words, the interface bonding between HMA overlay and PCC layer could still provide good adhesive ability after failure (that was when it encountered a large relative displacement).

Based on the above analysis, it is clear that temperature will affect the adhesive ability of the tack coat, and the interface bonding between HMA overlay and PCC layer can still provide considerable bonding strength after failure. The shear strength and IBC results indicate that emulsified asphalt, rubber asphalt, and virgin asphalt are the three suitable tack coat materials. Considering the different procedures and difficulty of construction, this study recommends the emulsified asphalt as the optimal tack coat material.

\subsection{Coupling Effects of Normal Stress and Temperature on} Interface Bonding. This section tried to study the coupling effects of normal stress and temperature on interface bonding. In the recommended tack coat, emulsified asphalt was adopted. Table 2 lists the main test conditions and average test results. The results under $1.5 \mathrm{MPa}$ and at $0^{\circ} \mathrm{C}$ were not listed in the table because the shear force was too high and exceeded the MTS range used in this study. It is concluded from Table 2 that lower temperature and higher normal stress were beneficial for interface bonding.

3.2.1. The Influence of Normal Stress. Further analysis was conducted to study the relationship between interface bonding strength and normal stress at different test temperatures. From Figure 6(a), it is obvious that the shear strength increased with the increase of normal stress at $0^{\circ} \mathrm{C}$. According to the test results, when the normal stress was $1.5 \mathrm{MPa}$, the shear force was higher than $100 \mathrm{kN}$, the maximum applied load of the MTS. Consequently, the interface bonding was very strong at $0^{\circ} \mathrm{C}$, so it could meet the adhesive requirements in most cases.

At $15^{\circ} \mathrm{C}$, the influence of normal stress was more significant. For example, the shear strength was increased by $50 \%$ when normal stress was changed from $0.5 \mathrm{MPa}$ to 1.0 $\mathrm{MPa}$, as shown in Figure 6(b). In addition, the shear strength was increased by $48.6 \%$ when normal stress was changed from 1.0 MPa to 1.5 $\mathrm{MPa}$. However, the enhancement effect of normal stress on the interface bonding strength was weakened as the temperature increased. As shown in Figure 6(e), the normal stress had a very limited influence on the shear strength when it was less than $0.5 \mathrm{MPa}$.

Figure 7 illustrates the relationship between normal stress and other interface bonding parameters at $30^{\circ} \mathrm{C}$, including the shear strength, residual strength, interface bonding coefficient, and residual ratio. It can be found from Figure 7 (a) that both shear strength and residual strength were positively correlated with normal stress, even though the increase rate of shear strength and residual ratio gradually slowed down. When normal stress increased from 0 to 1.5 $\mathrm{MPa}$, the shear strength increased from 0.3 to $0.9 \mathrm{MPa}$, and the residual strength increased from 0.07 to $0.7 \mathrm{MPa}$. However, the growth trend of IBC was not consistent with the increase of normal stress, which reduced at first and then 


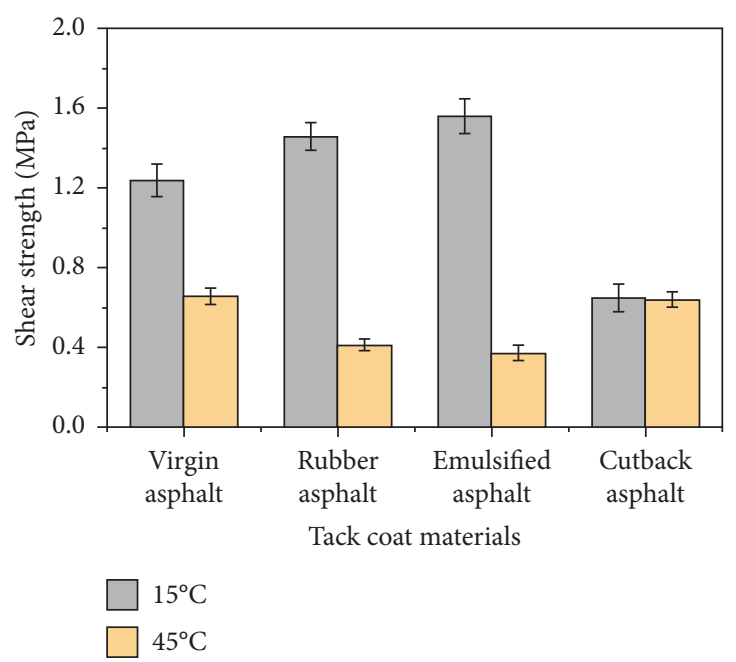

(a)

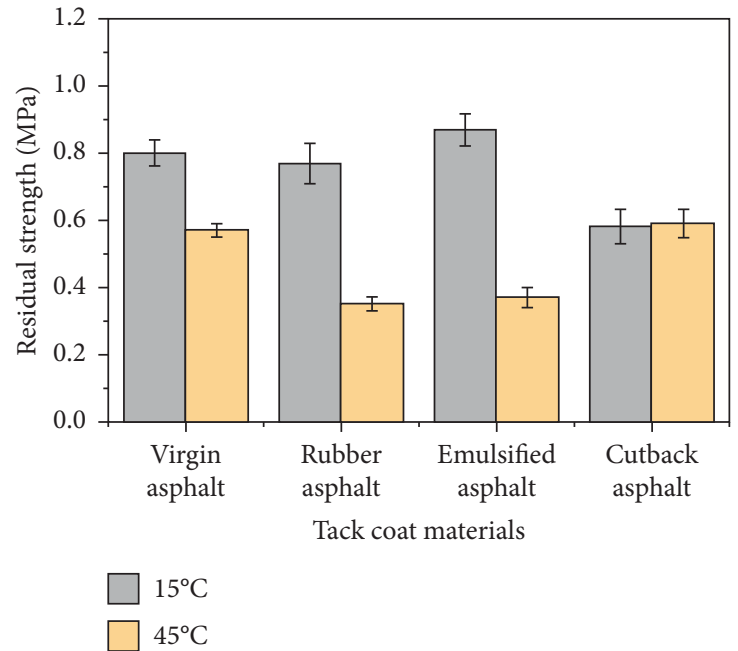

(c)

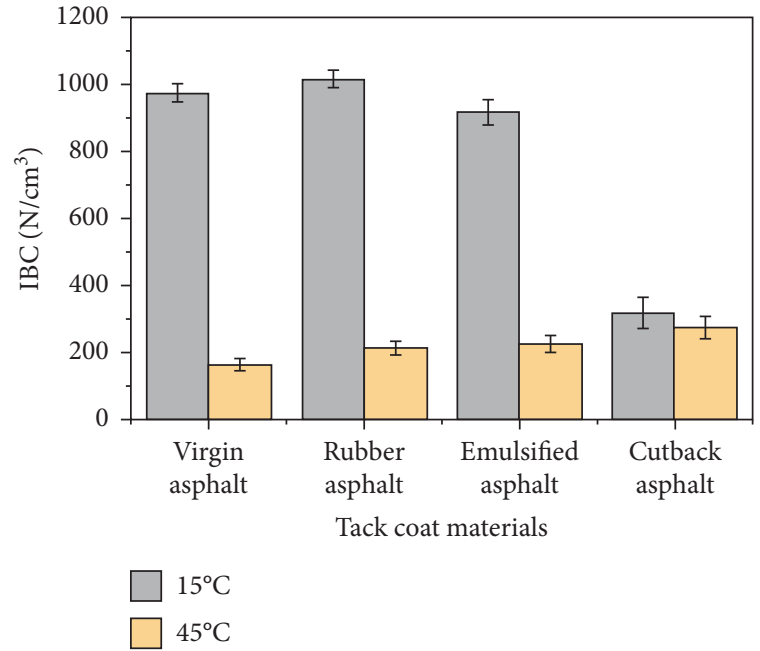

(b)

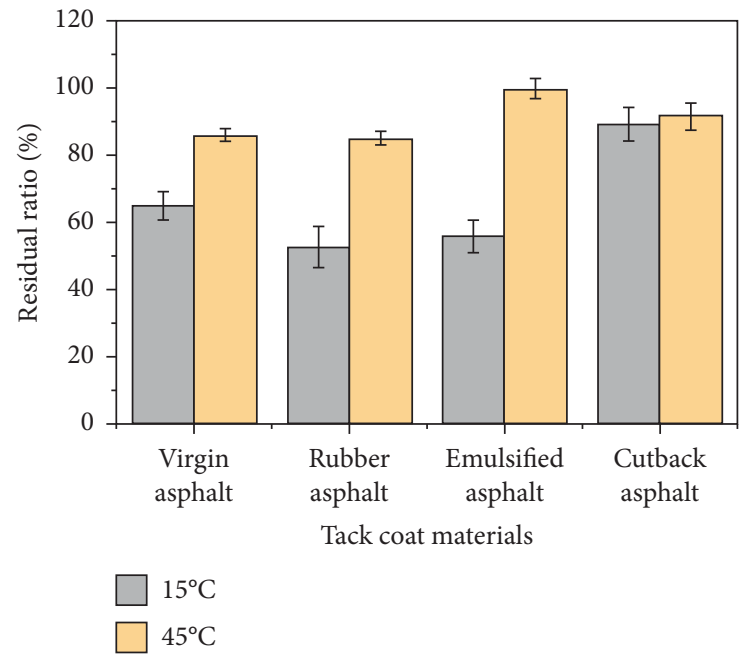

(d)

FIgURE 5: Test results of various tack coat materials. (a) Shear strength. (b) Interface bonding coefficient. (c) Residual strength. (d) Residual ratio.

TABLE 2: Test results from different combinations of normal stress and temperatures.

\begin{tabular}{|c|c|c|c|c|c|}
\hline Temperature $\left({ }^{\circ} \mathrm{C}\right)$ & Normal stress $(\mathrm{MPa})$ & Shear strength $(\mathrm{MPa})$ & IBC $\left(\mathrm{N} / \mathrm{cm}^{3}\right)$ & Residual strength (MPa) & Residual ratio (\%) \\
\hline \multirow{3}{*}{0} & 0 & 2.35 & 1445.33 & 0.00 & 0.00 \\
\hline & 0.5 & 3.11 & 1368.16 & 0.35 & 11.41 \\
\hline & 1.0 & 4.16 & 1415.66 & 0.80 & 19.35 \\
\hline \multirow{4}{*}{15} & 0 & 0.77 & 518.21 & 0.07 & 9.12 \\
\hline & 0.5 & 0.69 & 271.38 & 0.41 & 58.66 \\
\hline & 1.0 & 1.04 & 448.46 & 0.43 & 41.78 \\
\hline & 1.5 & 1.55 & 859.79 & 0.88 & 56.79 \\
\hline \multirow{4}{*}{30} & 0 & 0.28 & 161.46 & 0.14 & 48.19 \\
\hline & 0.5 & 0.36 & 158.37 & 0.30 & 82.61 \\
\hline & 1.0 & 0.93 & 417.43 & 0.71 & 75.65 \\
\hline & 1.5 & 1.15 & 343.00 & 1.01 & 87.20 \\
\hline \multirow{4}{*}{45} & 0 & 0.12 & 33.67 & 0.06 & 49.42 \\
\hline & 0.5 & 0.31 & 98.07 & 0.27 & 87.51 \\
\hline & 1.0 & 0.57 & 152.09 & 0.61 & 106.28 \\
\hline & 1.5 & 0.58 & 144.27 & 0.59 & 101.97 \\
\hline \multirow{4}{*}{60} & 0 & 0.05 & 17.78 & 0.03 & 56.87 \\
\hline & 0.5 & 0.39 & 100.75 & 0.33 & 83.60 \\
\hline & 1.0 & 0.38 & 445.05 & 0.41 & 106.22 \\
\hline & 1.5 & 0.37 & 223.72 & 0.37 & 99.79 \\
\hline
\end{tabular}




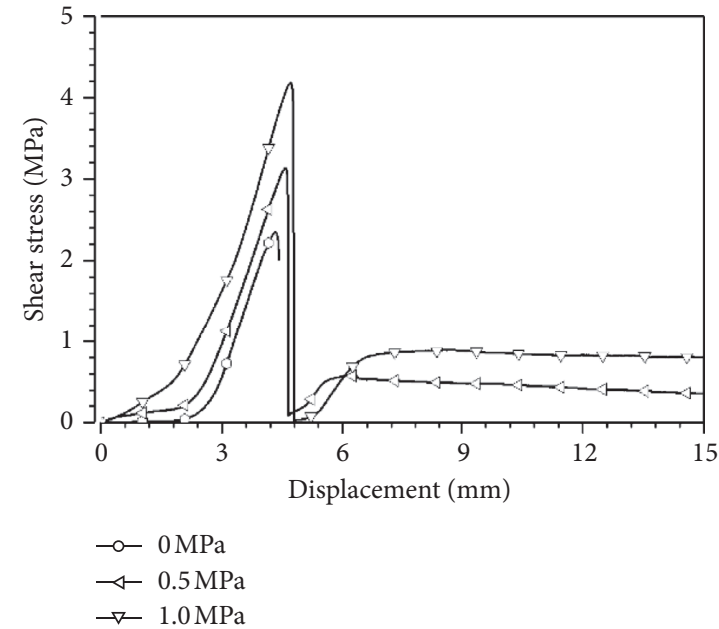

(a)

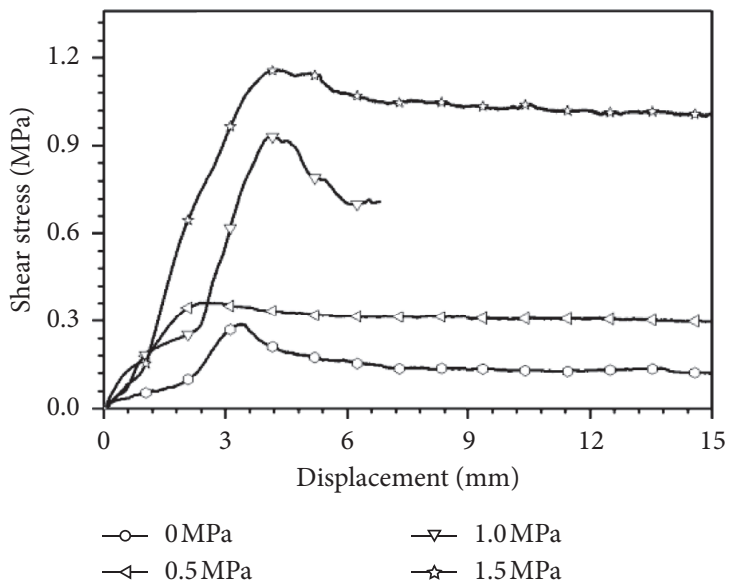

(c)

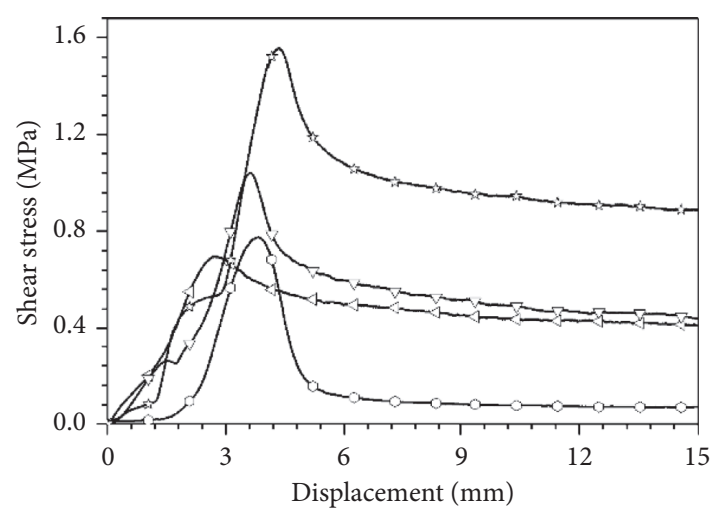

$$
\begin{array}{ll}
\multimap 0 \mathrm{MPa} & \rightarrow-1.0 \mathrm{MPa} \\
\smile-0.5 \mathrm{MPa} & \varpi-1.5 \mathrm{MPa}
\end{array}
$$

(b)

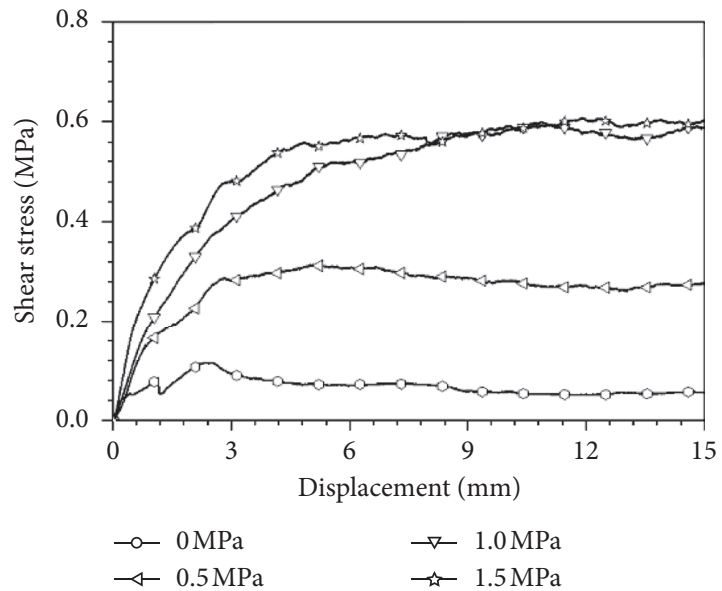

(d)

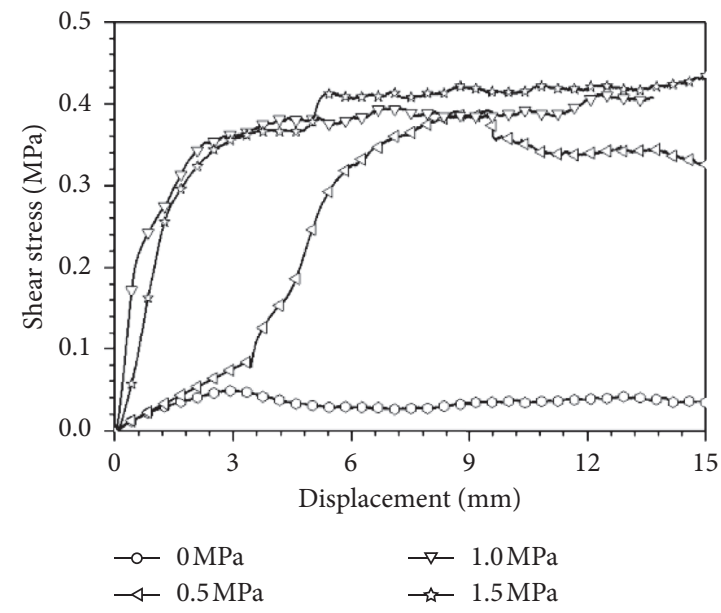

(e)

Figure 6: Shear stress-displacement curves under various normal stress. (a) At $0^{\circ} \mathrm{C}$. (b) At $15^{\circ} \mathrm{C}$. (c) At $30^{\circ} \mathrm{C}$. (d) At $45^{\circ} \mathrm{C}$. (e) At $60^{\circ} \mathrm{C}$. 

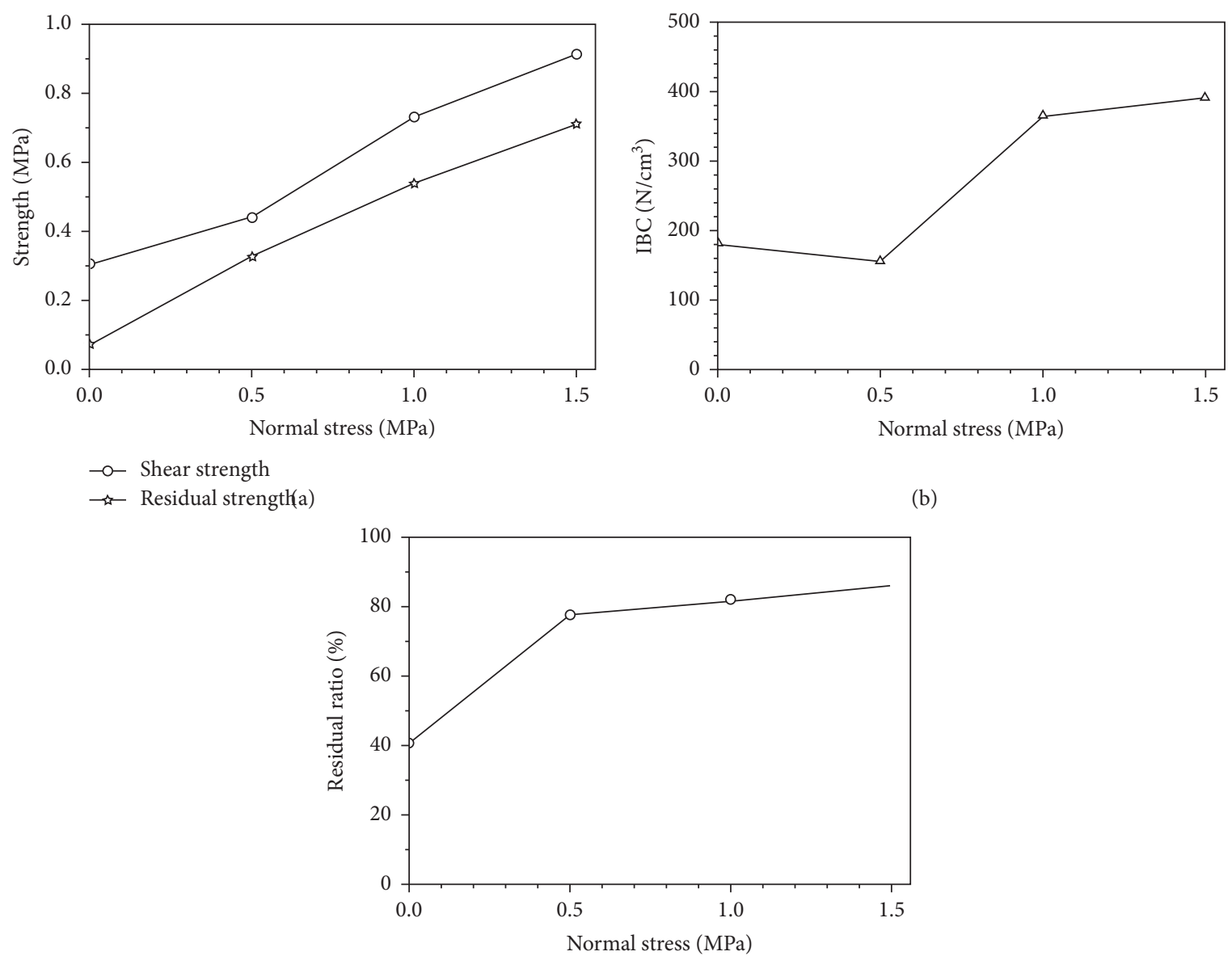

(c)

FigURE 7: Relationship between normal stress and other interface bonding parameters. (a) Shear strength and residual strength. (b) Interface bonding coefficient. (c) Residual ratio.

increased. In addition, the residual ratio also had positive correlation with normal stress. As shown in Figure 7(c), the residual ratio rapidly increased from $40.9 \%$ to $78.1 \%$ when the normal stress increased from 0 to $0.5 \mathrm{MPa}$, and then the increase ratio reduced significantly.

In conclusion, the normal stress benefited interface bonding strength, especially at a lower temperature. Higher normal stress can increase both residual strength and residual ratio, but it usually had a very limited influence on the failure mode of interface bonding.

3.2.2. The Influence of Temperature. To study the effects of temperature on the interface bonding, the shear strengthdisplacement curves were redrawn according to normal stress. As shown in Figure 8, as the temperature increased, the hump of the curves disappeared gradually. It was obvious that the temperature was related to the failure mode (i.e., plastic failure or brittle failure) of interface bonding, and low temperature tended to cause brittle failure. In contrast, only plastic failure would occur when the test temperature was not less than $45^{\circ} \mathrm{C}$ in this study. Additionally, the high temperature would significantly decrease the shear strength, no matter what the normal stress was.

The relationships between temperature and other interface bonding parameters under $1.0 \mathrm{MPa}$ normal stress are illustrated in Figure 9. Despite some slight fluctuations, both shear strength and IBC were negatively correlated with. However, the residual strength did not show any significant change when the temperature rose from 0 to $60^{\circ} \mathrm{C}$, which indicated that the temperature might not influence the residual strength. It was interesting that the residual ratio was positively related to the temperature because plastic failure was easier to occur at a high temperature, which would usually result in a higher residual rate.

In summary, temperature had a significant effect on interface bonding, and higher temperature would undoubtedly reduce the shear strength and interface bonding coefficient. Moreover, temperature played a dominant role in the failure mode of interface bonding. Specifically, interface bonding was more prone to plastic failure at high temperature but trended to encounter brittle failure at low temperature. 


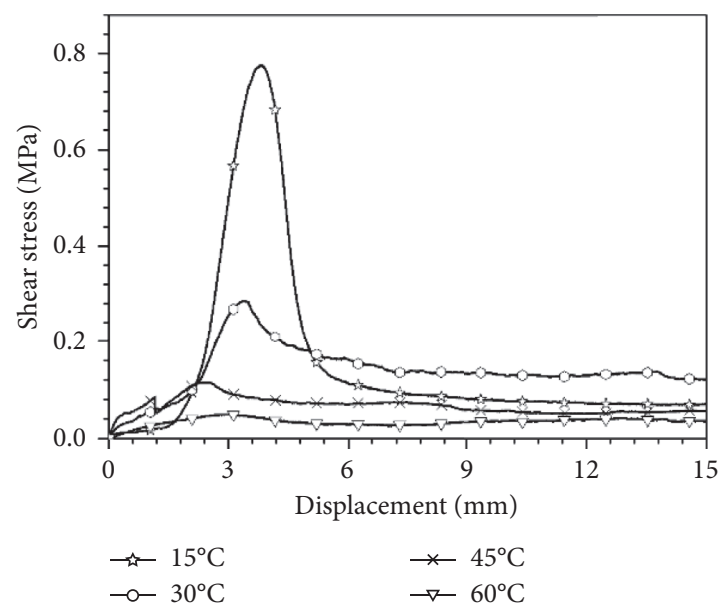

(a)

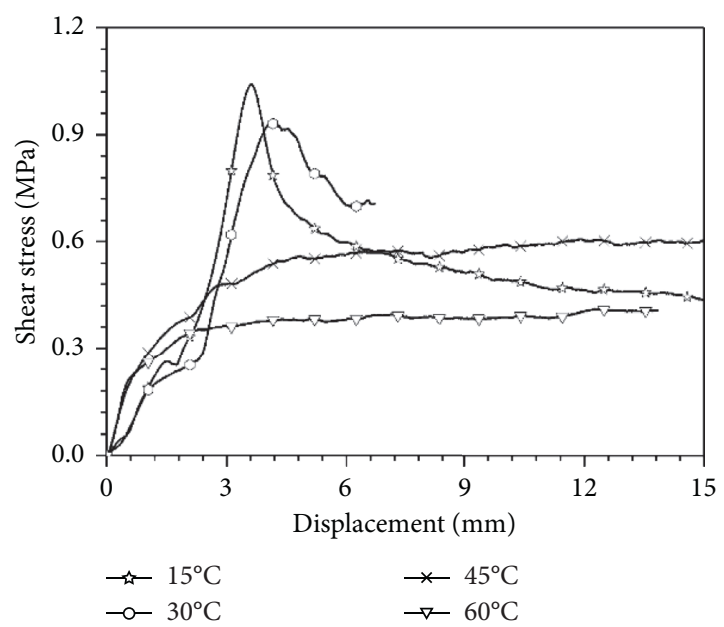

(c)

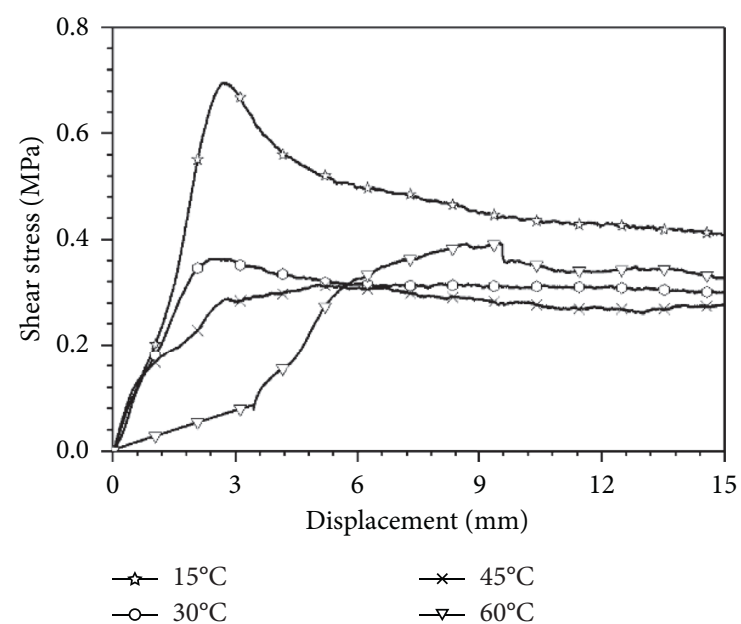

(b)

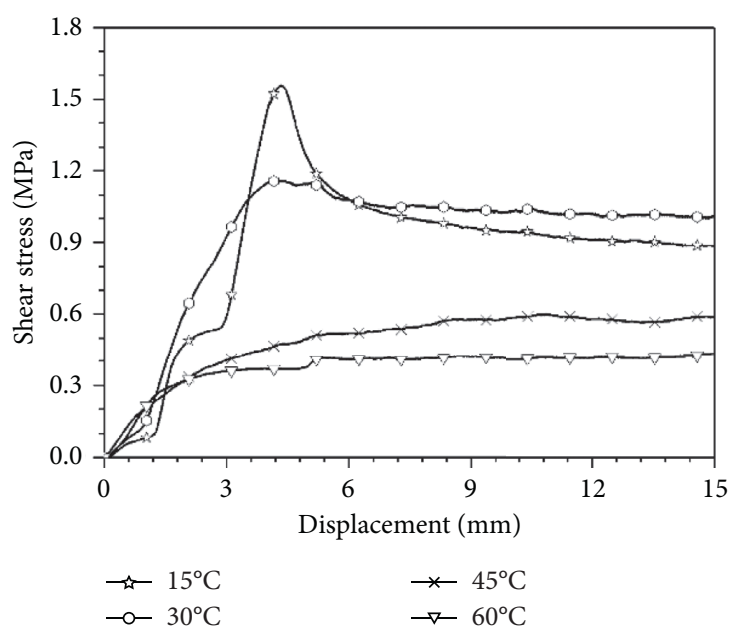

(d)

Figure 8: Shear stress-displacement curves at different temperatures. (a) $0 \mathrm{MPa}$, (b) $0.5 \mathrm{MPa}$, (c) $1.0 \mathrm{MPa}$, and (d) $1.5 \mathrm{MPa}$.

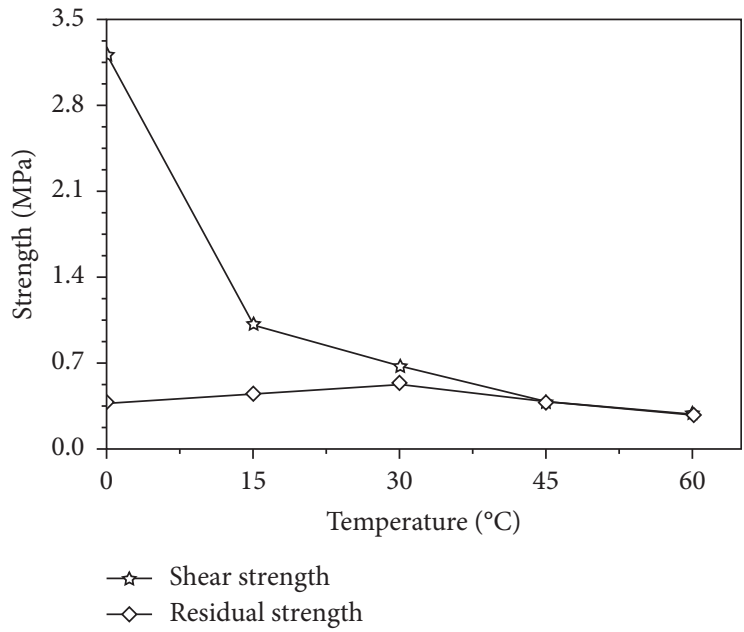

(a)

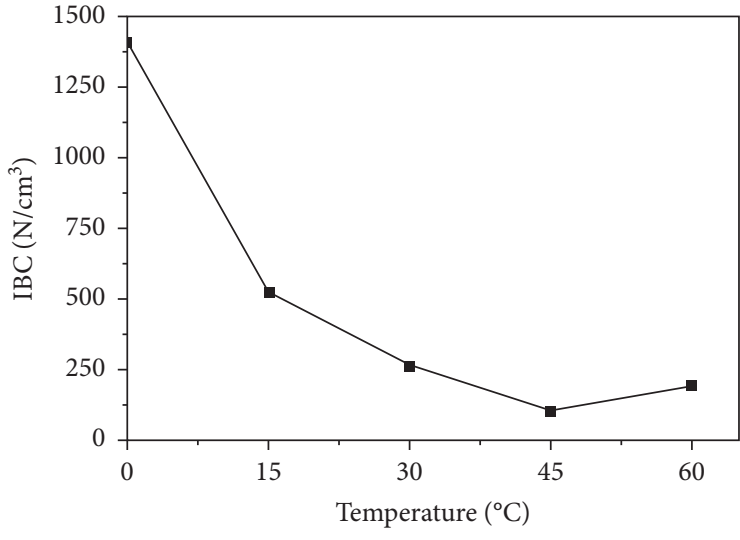

(b)

Figure 9: Continued. 


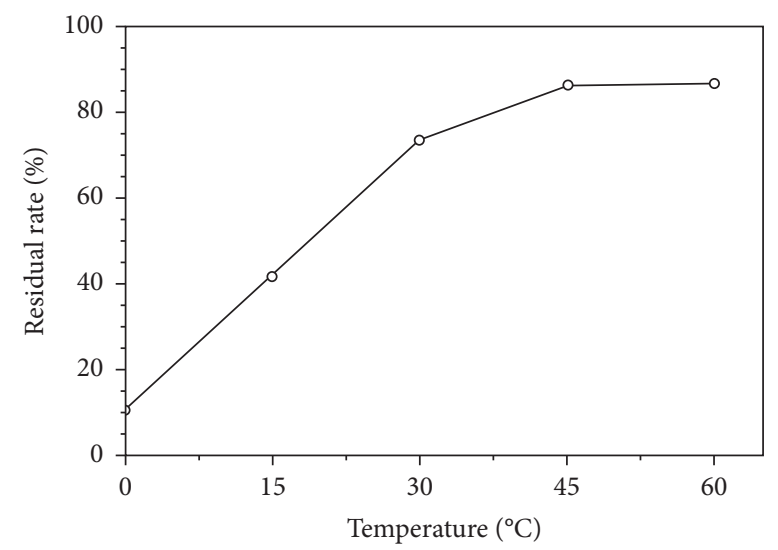

(c)

FIGURE 9: Relationship between temperature and other interface bonding parameters. (a) Shear strength and residual strength. (b) Interface bonding coefficient. (c) Residual ratio.

\section{Conclusions}

To study the characteristics of interface bonding comprehensively, a series of laboratory tests were conducted based on a self-designed direct shear test apparatus that can simultaneously apply shear force and normal stress on a specimen. Four kinds of tack coat materials were investigated under four different normal stresses and five temperatures. This research tried to analyze the coupling effects of normal stress and temperature on interface bonding. The key findings or conclusions were summarized as follows.

Temperature had a significant influence on the adhesive ability of the tack coat. A tack coat that had high shear strength at low temperature might not provide similar interface bonding strength at high temperature. Although emulsified asphalt, rubber asphalt, and virgin asphalt had a similar adhesive ability, the emulsified asphalt was recommended because of its simple construction method.

The interface between HMA overlay and PCC layer was still able to provide considerable bonding strength after failure, indicating that the damaged interface could still function. The interface bonding coefficient could be selected as an indicator to distinguish the failure mode of interface bonding.

Normal stress benefited interface bonding strength, especially at a lower temperature. Higher normal stress can increase both residual strength and residual ratio, but it usually had very limited impacts on the failure mode of interface bonding.

Temperature had a significant effect on interface bonding and played a dominant role in the failure mode of interface bonding. Specifically, the interface bonding was more prone to plastic failure at a high temperature, while it trended to encounter brittle failure at a low temperature.

\section{Data Availability}

The data used to support the findings of this study are available from the corresponding author upon request.

\section{Additional Points}

Highlights. A special direct shear test device was designed and manufactured to apply both normal stress and shear stress on the specimen. Different tack coat materials were tested and compared, and the optimal tack coat material was determined. The coupling effects of normal stress and temperature on interface bonding between Portland cement concrete and hot-mix asphalt mixture were analyzed.

\section{Conflicts of Interest}

The authors declare that they have no conflicts of interest.

\section{Acknowledgments}

The National Natural Science Foundation of China (U1433201 and U1333104) supported this work.

\section{References}

[1] S. Chun, K. Kim, J. Greene, and B. Choubane, "Evaluation of interlayer bonding condition on structural response characteristics of asphalt pavement using finite element analysis and full-scale field tests," Construction and Building Materials, vol. 96, pp. 307-318, 2015.

[2] D. Fordyce and K. Khweir, "Influence of layer bonding on the prediction of pavement life," in Proceedings of the ICETransport, vol. 156, no. 2, pp. 73-83, 2003.

[3] J. Ling, F. Wei, H. Zhao, Y. Tian, B. Han, and Z. A. Chen, "Analysis of airfield composite pavement responses using fullscale accelerated pavement testing and finite element method," Construction and Building Materials, vol. 212, pp. 596-606, 2019.

[4] A. Mateos, J. Harvey, J. Paniagua, F. Paniagua, and F. Liu, "Mechanical characterisation of concrete-asphalt interface in bonded concrete overlays of asphalt pavements," European Journal of Environmental and Civil Engineering, vol. 81, no. 89, pp. 1-11, 2012.

[5] S. Romanoschi and J. Metcalf, "Characterization of asphalt concrete layer interfaces," Transportation Research Record: 
Journal of the Transportation Research Board, vol. 1778, no. 1, pp. 132-139, 2011.

[6] D. Fordyce and K. Khweir, "Influence of layer bonding on the prediction of pavement life," Transport, vol. 156, no. 2, pp. 73-83, 2003.

[7] H. Ozer, I. L. Al-Qadi, H. Wang, and Z. Leng, "Characterisation of interface bonding between hot-mix asphalt overlay and concrete pavements: modelling and in-situ response to accelerated loading," International Journal of Pavement Engineering, vol. 13, no. 2, pp. 1-16, 2012.

[8] K. Liu, F. Wang, and X. Wang, Research on Interlaminar Instability Failure of Asphalt Overlay on Old Cement Pavement, The Annual Meeting of Transportation Research Board, Washington, DC, USA, 2012.

[9] M. Saghebfar and Y. M. Najjar, Evaluation of Interface Bond Strength of Asphalt Pavements, The Annual Meeting of Transportation Research Board, Washington, DC, USA, 2014.

[10] J. P. Zaniewski, S. F. Knihtila, and H. N. Rashidi, Evaluation of the Bond Strength of Asphalt OverlaysInternational Airfield and Highway Pavements Conference, Washington, DC, USA, 2015.

[11] J. Uzan, M. Livneh, and Y. Eshed, Investigation of Adhesion Properties Between Asphaltic-Concrete LayersAssociation of Asphalt Paving Technologists Proc, Washington, DC, USA, 1978.

[12] A. A. Molenaar, J. P. Heerkens, and J. M. Verhoeven, Effects of Stress Absorbing Membrane Interlayers Vol. 55, Association of Asphalt Paving Technologists Proc, Washington, DC, USA, 1986.

[13] D. Mrawira and D. J. Damude, "Revisiting the Effectiveness of Tack Coats in HMA Overlays: The Shear Strength of Tack Coats in Young Overlays," in Proceedings of the Annual Conference-Canadian Technical Asphalt Association, pp. 115-130, Ontario, Canada, December 1999.

[14] C. Sangiorgi, N. H. Thom, and A. C. Collop, "Assesment of bond condition using the Leutner shear test," Transport, vol. 156, no. 4, pp. 211-217, 2003.

[15] I. L. Alqadi, Tack Coat Optimization for HMA Overlays: Laboratory Testing, Civil Engineering Studies Illinois Center for Transportation, Illinois, USA, 2008.

[16] B. Han, J. Ling, X. Shu et al., "Resilient interface shear modulus for characterizing shear properties of pavement base materials," Journal of Materials in Civil Engineering, vol. 30, no. 12, Article ID 04018333, 2018.

[17] B. Han, J. Ling, X. Shu et al., "Quantifying the effects of geogrid reinforcement in unbound granular base," Geotextiles and Geomembranes, vol. 47, no. 3, pp. 369-376, 2019.

[18] M. S. Buchanan and M. E. Woods, Field Tack Coat Evaluator. Emulsions, 2004.

[19] A. T. Papagiannakis, L. Tashman, and K. Nam, Evaluation of the Influence of Tack Coat Construction Factors on the Bond Strength between Pavement Layers, Milling, Washington, DC, USA, 2006.

[20] E. P. Donovan, I. L. Al-Qadi, and A. Loulizi, "Optimization of tack coat application rate for geocomposite membrane on bridge decks," Transportation Research Record: Journal of the Transportation Research Board, vol. 1740, no. 1, pp. 143-150, 2000.

[21] A. Arulrajah, M. A. Rahman, J. Piratheepan, M. W. Bo, and M. A. Imteaz, "Evaluation of interface shear strength properties of geogrid-reinforced construction and demolition materials using a modified large scale direct shear testing apparatus," Journal of Materials in Civil Engineering, vol. 26, no. 5, pp. 1-9, 2013.
[22] AASHTO, Standard Method of Test for Determining the Interlayer Shear Strength (ISS) of Asphalt Pavement Layers, AASHTO, Washington, D.C, 2015.

[23] Z. Leng, H. Ozer, I. L. Al-Qadi, and S. H. Carpenter, "Interface bonding between hot-mix asphalt and various Portland cement concrete surfaces," Transportation Research Record: Journal of the Transportation Research Board, vol. 2057, no. 1, pp. 46-53, 2008.

[24] Z. Leng, I. L. Al-Qadi, S. Carpenter, and H. Ozer, "Interface bonding between hot-mix asphalt and various Portland cement concrete surfaces," Transportation Research Record: Journal of the Transportation Research Board, vol. 2127, no. 2127 , pp. 20-28, 2009.

[25] H. Zhao, J. Cao, and Y. Zheng, "Investigation of the interface bonding between concrete slab and asphalt overlay," Road Materials and Pavement Design, vol. 2, pp. 1-10, 2017.

[26] Z. Ge, H. Wang, Q. Zhang, and C. Xiong, "Glass fiber reinforced asphalt membrane for interlayer bonding between asphalt overlay and concrete pavement," Construction and Building Materials, vol. 101, pp. 918-925, 2015.

[27] L. A. Goodman, "Statistical methods for the mover-stayer model," Journal of the American Statistical Association, vol. 56, no. 296, pp. 841-8, 1961. 